\title{
Psychological Distress of Testing Positive for Human Papillomavirus at Routine Prenatal Visits: A Prospective Observational Study among Chinese Pregnant Women with Normal Cytology
}

\section{Yifan Hu}

Department of Obstetrics and Gynecology, Ren Ji Hospital, School of Medicine, Shanghai Jiao Tong University

\section{Liying Gu}

Department of Obstetrics and Gynecology, Ren Ji Hospital, School of Medicine, Shanghai Jiao Tong University

\section{Zubei Hong}

Department of Obstetrics and Gynecology, Ren Ji Hospital, School of Medicine, Shanghai Jiao Tong University

\section{Hong Yu}

Department of Obstetrics and Gynecology, Ren Ji Hospital, School of Medicine, Shanghai Jiao Tong University

\section{Yu Zhang}

Department of Obstetrics and Gynecology, Ren Ji Hospital, School of Medicine, Shanghai Jiao Tong University

\section{Jianhua Lin}

Department of Obstetrics and Gynecology, Ren Ji Hospital, School of Medicine, Shanghai Jiao Tong University

\section{Lihua Qiu}

Shanghai Key Laboratory of Gynecologic Oncology, Ren Ji Hospital, School of Medicine, Shanghai Jiao Tong University

\section{Wen Di ( $\nabla$ diwen163@163.com )}

State Key Laboratory of Oncogenes and Related Genes, Shanghai Cancer Institute, Ren Ji Hospital, School of Medicine, Shanghai Jiao Tong University

\section{Research Article}

Keywords: Papillomavirus Infections, Psycho-Oncology, Uterine Cervical Neoplasms, Early Detection of Cancer, Pregnant Women, Anxiety, Depression 
Posted Date: October 19th, 2021

DOI: https://doi.org/10.21203/rs.3.rs-447888/v2

License: (c) (i) This work is licensed under a Creative Commons Attribution 4.0 International License. Read Full License 


\section{Abstract}

Background To explore the psychological impact of the positive HPV result on pregnant women with normal cytology.

Methods The psychological distress level of HPV-positive women was compared with those of HPVnegative women before the results were notified. After the notification, the distress level of women in the HPV-positive group was assessed for the $2^{\text {nd }}$ time and $3^{\text {rd }}$ time before colposcopy and 2 weeks postcolposcopy. The lifestyle characteristics, knowledge of cervical cancer and screening behavior were compared between groups. Logistic regression was used to assess associations between sociodemographic, lifestyle, knowledge and risk of elevated distress level.

Results No statistical difference of the distress level (as measured by PHQ-9 and GAD-7) was found between HPV-positive and -negative women. Within HPV-positive group, low distress level remained through all three time-points, regardless of HPV subtypes or colposcopy diagnoses. Half of the participants were suboptimally screened before this study conducted; $7.6 \%$ were aware of the causal relationship between HPV and cervical cancer. Post-graduate degree was associated with elevated PHQ-9 score.

Conclusions HPV screening was unlikely to cause additional psychological distress among pregnant population in China.

\section{Background}

The cervical cancer burden in mainland China is heavy compared to those developed areas in the world, the incidence and mortality rate of which ranked sixth and seventh among all female cancer sites in 2020, according to International Agency for Research on Cancer (IARC). (1)

Because of the high coverage of population-based screening programmes in developed countries, for example, 3-year coverage of $80 \%$ in the US (2) and 3.5-year coverage of $69 \%$ in the UK, (3) cervical cancer screening during pregnancy in such areas may not play as important a role as in developing countries like China. Despite being free since 2009 in some rural regions, the lifetime coverage of cervical cancer screening among the targeted population was still under 50\%. (4) Even in urban areas like Shanghai, where conventional pap smear being the primary screening method in communities partly funded by the city's Family Planning Program, women were mostly opportunistic screened at gynecological outpatient units or spontaneously screened as a part of well-women checkup, although self-paid. The low coverage of cervical cancer screening in China called for urgent measures. Therefore, in 2017, the Chinese Preventive Medicine Association recommended all pregnant women with no screening history one year prior to pregnancy to undergo cervical cancer screening at their first prenatal visit. (5)

It is well accepted today that both primary HPV testing and combined HPV testing with cytology screening provide a more sensitive result than primary cytology screening. (6-8) The American Society for 
Colposcopy and Cervical Pathology (ASCCP) updated its cervical cancer screening management consensus in 2020 based on the results of not cytology, but HPV testing. (9) For otherwise healthy individuals, however, the benefit of testing positive for HPV may not outweigh the harm through overtreatment, including time, financial, and psychological costs of the women.

Many quantitative and qualitative studies have suggested that testing positive for HPV might be associated with increased distress and anxiety levels among non-pregnant populations. (10-12) Be that as it may, in some studies, participants were given information specifically including the sexually transmitting nature of HPV, prior to the examination, which might have increased the anxiety of the participants. Moreover, most cross-sectional studies were unable to determine the psychological wellbeing of the participants before testing positive for HPV, therefore selection bias cannot be excluded as a factor which influences the high anxiety level detected in the HPV positive population. In fact, one study assessing the psychological damage caused by revealing the positive HPV result to HPV-positive women in a large randomized trial (the ARTISTIC trial) (13) showed that receiving an HPV-positive result did not add significant psychological distress compared with participants in the control group, whose HPV results were also positive but were concealed. Interestingly, when compared within groups, concealed or not concealed, the HPV-positive women always showed higher levels of distress and anxiety compared with the HPV-negative participants. This may be subject to selection bias, as there were psychological and behavioral differences between the women who were HPV-positive and -negative, which suggests that previous studies may have amplified the adverse psychological impacts caused by the HPV testing alone. Nevertheless, none of the studies above were targeted on the pregnant population. Typically, pregnancy is a time of emotional well-being for women, but for some women it is possible that pregnancy may worsen the existing mental illness. (14) Testing positive for a sexually transmitted infection (STI) like HPV would cause even more stigma in a society that values modesty and monogamous like China. (15)

Thus, our study aimed to explore the psychological impact of the positive HPV test result on pregnant women by comparing psychological distress level between screened-positive and -negative group, and among pre-notification, pre-colposcopy, and 2 weeks post-colposcopy in the screened-positive group.

\section{Methods}

\section{Study design}

A prospective observational design was employed to assess pregnant women's psychological distress before the notification of a positive-HPV-and-normal-cytology result, as well as before the colposcopy evaluation and 2 weeks after. The result notification and colposcopy evaluation were 2 weeks apart.

\section{HPV genotyping and cytology}

Two endocervical brush samples were taken from the participants for liquid based cytology (Thinprep) and HPV genotyping (Hybribio), as the co-testing. The cytology results were evaluated according to the 
Bethesda system as Negative for intraepithelial lesion or malignancy (NILM), atypical squamous cells of undetermined significance (ASC-US), low-grade squamous intraepithelial lesion (LSIL), and high-grade squamous intraepithelial lesion (HSIL). An abnormal cytology result was defined as ASC-US or above, and a positive HPV result referred to testing positive for any of the 13 high-risk subtypes. The HPV detection subtypes included 15 high-risk types $(16,18,31,33,35,39,45,51,52,53,56,58,59,66$ and 68) and 6 low-risk types $(6,11,42,43,44$ and 81$)$. The infection of high- risk HPV was defined as HPV positive.

\section{Participants}

From July, 1, 2017 to December, 31, 2017, pregnant women who had entered their second trimester undergoing combined HPV and cytology screening, the 'co-testing', were enrolled. Women with previously diagnosed mental illness, younger than 25 years of age, and had any obstetrics complications too serious to continue pregnancy were excluded. The positive HPV results were notified by the first author (a female researcher) by phone after the baseline psychological questionnaire was filled out. Most women that were invited to the colposcopy did not further ask the meaning of the screening results over the phone. For the inquiries regarding HPV, the first author responded with the following statements: (a) HPV is highly prevalent; (b) Persistent HPV infection is a prerequisite for cervical pre-malignancy and, eventually, cervical cancer; and (c) Evaluation under colposcopy is an effective way to determine whether there is a lesion on the cervix. The interview via telephone lasted 2-5 minutes per participant. Two weeks after the notification, participants were observed under colposcopy to rule out any cervical lesion and, if high-grade lesion was detected, the biopsy was done with fully consent of the participant, according to the study protocol. The second and third psychological evaluations were done before the colposcopy and 2 weeks after.

We also included a control group who had received a normal co-testing result. The psychological evaluation was done only once before the notification of the result (the baseline).

\section{Questionnaire}

The psychological distress questionnaire (in Chinese Mandarin language) included the Generalized Anxiety Disorder-7 scale (GAD-7) and the Patient Health Questionnaire-9 (PHQ-9) for anxiety and depression. We selected these two screening instruments considering that (a) they can easily be completed within 5 minutes, (b) questions are referring to symptoms during the last 2 weeks, which is coherent with the notification-colposcopy period, and (c) they were both validated for pregnancy populations, (16-18) as recommended by ACOG and NICE. $(19,20)$

Both PHQ-9 and GAD-7 have been developed from the original Patient Health Questionnaire (PHQ) with nine and seven questions each. (21) The PHQ-9 is composed of the nine criteria on which the diagnosis of depression is based in the Diagnostic and Statistical Manual of Mental Disorders IV (DSM-IV) (22) and 
scores can range from 0 to 27, with 5, 10, 15 and 20 representing mild, moderate, moderately severe and severe levels of depressive symptoms. Similarly, the GAD-7 can also be used as a continuous measure with scores ranging from 0 to 21 and cutoff points of 5,10 and 15 representing mild, moderate and severe anxiety symptoms.

The demographic data and lifestyle factors were also collected, followed by questions regarding screening behavior and knowledge of cervical cancer. Sexual debut under the age of 21 was deemed early in our study, according to an epidemiologic survey conducted in China in which the median age of sexual debut among women aged 25-44 years old was 22. (23)

\section{Ethical considerations}

The study was approved by Ren Ji Hospital Ethics Committee (2018[026]). All methods were carried out in accordance with the rules of the Declaration of Helsinki. All participants provided written informed consent before the cervical cancer screening.

\section{Statistical analysis}

Continual variables were presented as means (standard deviations, SD) or median (interquartile ranges, $P_{25} \sim P_{75}$ ). Categorical data were presented as frequencies (percentages). Univariate comparisons between HPV-positive and -negative groups were undertaken using the Pearson Chi-square test, exact Chisquare test, T-test, or Mann-Whitney test. Univariate and multivariate logistic regression analysis was employed to identify women's lifestyle factors that were associated with HPV positivity. Friedman's test and the Wilcoxon's test were employed to detect changes of psychological scores in the HPV-positive group between the first two time-points, and among all three time-points. Analyses were carried out using SPSS v25, and p-value $<0.05$ was considered statistically significant.

\section{Results}

\section{Characteristics of the study participants}

Four hundred and eighty-three pregnant women were invited to take part during the study period, of which 23 were excluded because of spontaneous abortion before cervical cancer screening started $(n=2)$, and refusal to follow-up ( $n=21$ ) (Figure 1). Eighty-two HPV-positive women and 378 HPV-negative women with normal cytology results were included in the study.

The mean age of the participants at enrollment was $30.8( \pm 4.0)$ years, and the gestational age was 21.2 ( \pm 3.5) weeks. Most of the pregnant women were married (98.3\%), workwomen (85.6\%), and college graduate $(80.0 \%)$. None of the participants were smokers during pregnancy and a few were exposed to passive smoking (5.4\%). Among past smokers (3.5\%), all women had quitted smoking 1 to 5 years prior to pregnancy or once pregnancy was confirmed. The HPV-positive women were more likely to be 'older 
mothers' (above 35 years of age, $30.5 \%$ vs $17.5 \%, p=0.007$ ). There was no significant difference in the $\mathrm{BMI}$, birthplace, and socioeconomic status between HPV-positive and -negative women (Table 1).

Most women were pregnant for the first time (42.2\%), while $38.9 \%$ had given birth to more than one child and $6.1 \%$ had had over 3 abortions. Several participants refused to answer the questions regarding sexual debut $(n=2)$ and the number of sexual partners $(n=1)$. Of those who answered, $36.6 \%$ and $20.2 \%$ $\left(X^{2}=10.15, p=0.002\right)$ women began sexual intercourse before the age of 21 (data not shown), whereas $17.1 \%$ and $6.4 \%\left(\chi^{2}=24.05, p<0.001\right)$ had three or more lifetime partners in the HPV-positive and negative groups, respectively. Regarding contraception methods, most women had never used an intrauterine device (IUD) (89.0\% vs $92.3 \%$ ), and more women had taken the oral contraceptives (mostly emergency OCs) in the HPV-positive group $\left(52.4 \%\right.$ vs $\left.31.5 \%, \chi^{2}=12.98, p<0.001\right)$ (Table 1).

Table 1. Sample characteristics. 


\begin{tabular}{|c|c|c|c|c|c|}
\hline & & Total & $\mathrm{HPV}+$ & HPV - & $P$ \\
\hline & & $N=460$ & $\mathrm{~N}=82$ & $\mathbf{N}=378$ & \\
\hline Age, years & Mean (SD) & 30.8 & 31.5 & 30.7 & $0.007 * *$ \\
\hline & & $(4.0)$ & $(4.1)$ & (3.9) & \\
\hline Gestational age, weeks & Mean (SD) & 21.2 & 20.8 & 21.2 & 0.251 \\
\hline & & $(3.5)$ & $(3.1)$ & $(3.6)$ & \\
\hline $\mathrm{BMI}^{\dagger}$ & $\sim 18.49$ & $26(5.7)$ & $7(8.5)$ & $19(5.1)$ & 0.068 \\
\hline & $18.5 \sim 23.99$ & 259 & & 206 & \\
\hline & & $(56.6)$ & $(64.6)$ & (54.8) & \\
\hline & $24 \sim 27.99$ & 130 & 14 & 116 & \\
\hline & & $(28.4)$ & $(17.1)$ & (30.9) & \\
\hline & $28 \sim$ & $43(9.4)$ & $8(9.8)$ & $35(9.3)$ & \\
\hline Education & Less than high & $34(7.4)$ & 11 & $23(6.1)$ & 0.069 \\
\hline & school & & $(13.4)$ & & \\
\hline & High school & 58 & $9(11.0)$ & 49 & \\
\hline & graduate & $(12.6)$ & & $(13.0)$ & \\
\hline & College graduate & 368 & 62 & 306 & \\
\hline & & $(80.0)$ & $(75.6)$ & $(81.0)$ & \\
\hline Employment ${ }^{\ddagger}$ & Employed & 385 & 68 & 317 & 0.487 \\
\hline & & $(85.6)$ & (82.9) & $(86.1)$ & \\
\hline & Unemployed & 65 & 14 & 51 & \\
\hline & & $(14.4)$ & $(17.1)$ & (13.9) & \\
\hline Birthplace & Shanghai & 328 & 58 & 270 & 0.894 \\
\hline & & $(71.3)$ & $(70.7)$ & $(71.4)$ & \\
\hline & Other Provinces & 132 & 24 & 108 & \\
\hline & & $(28.7)$ & $(29.3)$ & $(28.6)$ & \\
\hline Annual income (CNY) ${ }^{\S}$ & $\sim 30,000$ & $19(4.2)$ & $6(7.4)$ & $13(3.5)$ & 0.198 \\
\hline & $30,001 \sim 120,000$ & 292 & 52 & 240 & \\
\hline & & $(64.3)$ & $(64.2)$ & $(64.3)$ & \\
\hline & $120,001 \sim 240,000$ & 99 & 13 & 86 & \\
\hline & & $(21.8)$ & $(16.0)$ & $(23.1)$ & \\
\hline & $240,001 \sim$ & $44(9.7)$ & 10 & $34(9.1)$ & \\
\hline & & & $(12.3)$ & & \\
\hline Marital status & Single / divorced & $8(1.7)$ & $0(0.0)$ & $8(2.1)$ & 0.361 \\
\hline & Married & 452 & 82 & 370 & \\
\hline & & $(98.3)$ & $(100.0)$ & $(97.9)$ & \\
\hline Tobacco smoking before & Never & 444 & 77 & 367 & 0.178 \\
\hline pregnancy & & $(96.5)$ & $(93.9)$ & $(97.1)$ & \\
\hline & Yes & $16(3.5)$ & $5(6.1)$ & $11(2.9)$ & \\
\hline
\end{tabular}




\begin{tabular}{|c|c|c|c|c|c|}
\hline $\begin{array}{l}\text { Passive smoking during } \\
\text { pregnancy }\end{array}$ & $\begin{array}{l}\text { Never } \\
\text { Yes }\end{array}$ & $\begin{array}{l}435 \\
(94.6) \\
25(5.4)\end{array}$ & $\begin{array}{l}76 \\
(92.7) \\
6(7.3)\end{array}$ & $\begin{array}{l}359 \\
(95.0) \\
19(5.0)\end{array}$ & 0.407 \\
\hline Age at menarche & Mean (SD) & $\begin{array}{l}13.8 \\
(1.4) \\
\end{array}$ & $\begin{array}{l}13.9 \\
(1.5) \\
\end{array}$ & $\begin{array}{l}13.8 \\
(1.4) \\
\end{array}$ & 0.098 \\
\hline Age at sexual debut ${ }^{\dagger}$ & Mean (SD) & $\begin{array}{l}23.5 \\
(3.3) \\
\end{array}$ & $\begin{array}{l}22.8 \\
(3.6) \\
\end{array}$ & $\begin{array}{l}23.7 \\
(3.2) \\
\end{array}$ & $0.002 * *$ \\
\hline Age at first pregnancy $^{\dagger}$ & Mean (SD) & $\begin{array}{l}27.2 \\
(3.8)\end{array}$ & $\begin{array}{l}28.1 \\
(4.3)\end{array}$ & $\begin{array}{l}27.0 \\
(3.6)\end{array}$ & 0.760 \\
\hline Lifetime sexual partners $\pi$ & $\begin{array}{l}1 \\
2\end{array}$ & $\begin{array}{l}324 \\
(70.6) \\
97 \\
(21.2) \\
38(8.3)\end{array}$ & $\begin{array}{l}40 \\
(48.8) \\
28 \\
(34.1) \\
14 \\
(17.1) \\
\end{array}$ & $\begin{array}{l}284 \\
(75.3) \\
69 \\
(18.3) \\
24(6.4)\end{array}$ & $\begin{array}{l}<0.001 \\
* * *\end{array}$ \\
\hline Number of pregnancies & $\begin{array}{l}1 \\
2\end{array}$ & $\begin{array}{l}194 \\
(42.2) \\
131 \\
(28.5) \\
135 \\
(29.3)\end{array}$ & $\begin{array}{l}39 \\
(47.6) \\
18 \\
(22.0) \\
25 \\
(30.5)\end{array}$ & $\begin{array}{l}155 \\
(41.0) \\
113 \\
(29.9) \\
110 \\
(29.1)\end{array}$ & 0.329 \\
\hline Number of deliveries & $\begin{array}{l}0 \\
1 \sim\end{array}$ & $\begin{array}{l}281 \\
(61.1) \\
179 \\
(38.9)\end{array}$ & $\begin{array}{l}56 \\
(68.3) \\
26 \\
(31.7)\end{array}$ & $\begin{array}{l}225 \\
(59.5) \\
153 \\
(40.5)\end{array}$ & 0.140 \\
\hline Number of abortions & $\begin{array}{l}0 \sim 2 \\
3 \sim\end{array}$ & $\begin{array}{l}432 \\
(93.9) \\
28(6.1)\end{array}$ & $\begin{array}{l}79 \\
(96.3) \\
3(3.7)\end{array}$ & $\begin{array}{l}353 \\
(93.4) \\
25(6.6)\end{array}$ & 0.446 \\
\hline Used OC & $\begin{array}{l}\text { Never } \\
\text { Yes }\end{array}$ & $\begin{array}{l}298 \\
(64.8) \\
162 \\
(35.2) \\
\end{array}$ & $\begin{array}{l}39 \\
(47.6) \\
43 \\
(52.4) \\
\end{array}$ & $\begin{array}{l}259 \\
(68.5) \\
119 \\
(31.5) \\
\end{array}$ & $\begin{array}{l}<0.001 \\
* * *\end{array}$ \\
\hline Used IUD $\pi$ & $\begin{array}{l}\text { Never } \\
\text { Yes }\end{array}$ & $\begin{array}{l}421 \\
(91.7) \\
38(8.3)\end{array}$ & $\begin{array}{l}73 \\
(89.0) \\
9(11.0)\end{array}$ & $\begin{array}{l}348 \\
(92.3) \\
29(7.7)\end{array}$ & 0.328 \\
\hline
\end{tabular}

CNY, Chinese Yuan; OC, oral contraceptives; IUD, intrauterine device.

$* \mathrm{p}<0.05$

$* * \mathrm{p}<0.01$

$* * * \mathrm{p}<0.001$ 

†. 2 missing
‡. 10 missing
§. 6 missing
ף. 1 missing

\section{Knowledge of cervical cancer and screening history}

The proportion of those who self-reported knowing cervical cancer, HPV and screening methods was $62.4 \%, 37.2 \%$ and $29.3 \%$, respectively. There was no difference in cervical cancer knowledge between the groups. The screening rate before current pregnancy was inadequate; only $32.2 \%$ of women were regularly screened previously, while $20.7 \%$ were opportunistically screened (Table 2 ).

Table 2. Cervical cancer knowledge and screening history. 


\section{Total HPV HPV - $P$}

\begin{tabular}{lll}
\multicolumn{3}{c}{+} \\
\hline $\mathbf{N}=$ & $\mathbf{N}=$ & $\mathbf{N}=$ \\
460 & 82 & 378
\end{tabular}

Knowledge of CC

"Have you heard of cervical cancer?" No

$\begin{array}{lllll}\text { No } & 173 & 38 & 135 & 0.072\end{array}$

"Do you know the relationship between

Yes

(37.6) (46.3) (35.7)

HPV and CC?”

\begin{tabular}{lllll} 
& $(62.4)$ & $(53.7)$ & $(64.3)$ & \\
\cline { 1 - 3 } Not really & 289 & 51 & 238 & 0.977 \\
& $(62.8)$ & $(62.2)$ & $(63.0)$ & \\
Maybe a & 136 & 25 & 111 & \\
little & $(29.6)$ & $(30.5)$ & $(29.4)$ & \\
Yes & 35 & 6 & 29 &
\end{tabular}

\begin{tabular}{|c|c|c|c|c|c|}
\hline \multirow{4}{*}{ "Do you know the screening methods?" } & & (7.6) & $(7.3)$ & (7.7) & \\
\hline & No & 325 & 54 & 271 & \multirow[t]{3}{*}{0.292} \\
\hline & & (70.3) & (65.9) & (71.7) & \\
\hline & Yes & $\begin{array}{l}135 \\
(29.3)\end{array}$ & $\begin{array}{l}28 \\
(34.1)\end{array}$ & $\begin{array}{l}107 \\
(28.3)\end{array}$ & \\
\hline
\end{tabular}

Screening history

"Have you been screened for CC?"

Never

\begin{tabular}{lllll} 
Never & 217 & 41 & 176 & 0.572 \\
& $(47.2)$ & $(50.0)$ & $(46.6)$ & \\
\cline { 1 - 3 } Yes & 243 & 41 & 202 & \\
& $(52.8)$ & $(50.0)$ & $(53.4)$ &
\end{tabular}
screening?"

"If so, when was the last time of the

\begin{tabular}{lllll}
\hline$\sim 1$ year & 164 & 24 & 140 & 0.133 \\
& $(35.7)$ & $(29.3)$ & $(37.0)$ &
\end{tabular}

$\begin{array}{llll}1 \sim 3 \text { years } & 59 & 9 & 50\end{array}$

$\begin{array}{llll} & (12.8) & (11.0) & (13.2) \\ 3 \sim 5 \text { years } & 12 & 5 & 7(1.9)\end{array}$

$\begin{array}{llll} & (2.6) & (6.1) & \\ 5 \sim \text { years } & 8(1.7) & 3 & 5(1.3)\end{array}$

"What was the screening method(s)?"

\begin{tabular}{llll}
\hline TCT & 27 & 7 & 20 \\
& $(5.9)$ & $(8.5)$ & $(5.3)$ \\
HPV & $8(1.7)$ & 1 & $7(1.9)$ \\
& & $(1.2)$ & \\
\hline TCT + HPV & 55 & 13 & 42 \\
& $(12.0)$ & $(15.9)$ & $(11.1)$ \\
Pap smear & 29 & 5 & 24
\end{tabular}




\begin{tabular}{|c|c|c|c|c|c|}
\hline & \multicolumn{2}{|r|}{ (6.3) } & $(6.1)$ & $(6.3)$ & \\
\hline & Pap smear + & 18 & 3 & 15 & \\
\hline & Inknown & $(3.9)$ & 12 & 94 & \\
\hline & & $(23.0)$ & $(14.6)$ & $(24.9)$ & \\
\hline \multirow[t]{2}{*}{ "Were you regularly screened?" } & No & $\begin{array}{l}95 \\
(20.7)\end{array}$ & $\begin{array}{l}16 \\
(19.5)\end{array}$ & $\begin{array}{l}79 \\
(20.9)\end{array}$ & 0.852 \\
\hline & Yes & $\begin{array}{l}148 \\
(32.2)\end{array}$ & $\begin{array}{l}25 \\
(30.5)\end{array}$ & $\begin{array}{l}123 \\
(32.5)\end{array}$ & \\
\hline \multirow[t]{5}{*}{ "If so, how often were you screened?" } & $\begin{array}{l}\text { Every } 6 \\
\text { months }\end{array}$ & $5(1.1)$ & $\begin{array}{l}2 \\
(2.4)\end{array}$ & $3(0.8)$ & 0.230 \\
\hline & Every year & $\begin{array}{l}126 \\
(27.4)\end{array}$ & $\begin{array}{l}20 \\
(24.4)\end{array}$ & $\begin{array}{l}106 \\
(28.0)\end{array}$ & \\
\hline & $\begin{array}{l}\text { Every } 2 \\
\text { years }\end{array}$ & $\begin{array}{l}13 \\
(2.8)\end{array}$ & $\begin{array}{l}1 \\
(1.2)\end{array}$ & $\begin{array}{l}12 \\
(3.2)\end{array}$ & \\
\hline & $\begin{array}{l}\text { Every } 3 \\
\text { years }\end{array}$ & $3(0.7)$ & $\begin{array}{l}2 \\
(2.4)\end{array}$ & $1(0.3)$ & \\
\hline & $\begin{array}{l}\text { Every } 5 \\
\text { years }\end{array}$ & $1(0.2)$ & $\begin{array}{l}0 \\
(0.0)\end{array}$ & $1(0.3)$ & \\
\hline \multirow[t]{4}{*}{$\begin{array}{l}\text { "How many times have you been } \\
\text { screened?" † }\end{array}$} & 1 & $\begin{array}{l}84 \\
(18.3)\end{array}$ & $\begin{array}{l}13 \\
(15.9)\end{array}$ & $\begin{array}{l}71 \\
(18.8)\end{array}$ & 0.984 \\
\hline & $2 \sim 4$ & $\begin{array}{l}111 \\
(24.1)\end{array}$ & $\begin{array}{l}20 \\
(24.4)\end{array}$ & $\begin{array}{l}91 \\
(24.1)\end{array}$ & \\
\hline & $5 \sim$ & $\begin{array}{l}36 \\
(7.8)\end{array}$ & $\begin{array}{l}7 \\
(8.5)\end{array}$ & $\begin{array}{l}29 \\
(7.7)\end{array}$ & \\
\hline & Not sure & $7(1.5)$ & $\begin{array}{l}1 \\
(1.2)\end{array}$ & $6(1.9)$ & \\
\hline \multirow[t]{3}{*}{$\begin{array}{l}\text { "Have you been tested positive for } \\
\text { HPV?" }\end{array}$} & Never & $\begin{array}{l}104 \\
(22.6)\end{array}$ & $\begin{array}{l}14 \\
(17.1)\end{array}$ & $\begin{array}{l}90 \\
(23.8)\end{array}$ & $\begin{array}{l}<0.001 \\
* * *\end{array}$ \\
\hline & Yes & $\begin{array}{l}21 \\
(4.6)\end{array}$ & $\begin{array}{l}12 \\
(14.6)\end{array}$ & $9(2.4)$ & \\
\hline & Not sure & $2(0.4)$ & $\begin{array}{l}1 \\
(1.2)\end{array}$ & $1(0.3)$ & \\
\hline
\end{tabular}

CC, cervical cancer.

*** $\mathrm{p}<0.001$

†. 5 missing 


\section{Anxiety and depression}

The baseline scores of PHQ-9 and GAD-7 between the HPV-positive and -negative participants were comparable. The Mann-Whitney test showed no significant difference between the two groups. The median baseline scores of PHQ-9 and GAD-7 were $2(0$ - 4) and $1(0$ - 2) in the HPV-positive group, and 2 $(0-4)$ and $1(0-3)$ in the HPV-negative group. Most of the participants were non-depressed and nonanxious (Table 3).

Table 3. Psychological well-being at baseline.

\begin{tabular}{lllll}
\hline & & $\begin{array}{l}\text { HPV }+ \\
(\mathrm{N}=82)\end{array}$ & $\begin{array}{l}\text { HPV }- \\
(\mathrm{N}=378)\end{array}$ & P \\
\cline { 1 - 4 } PHQ-9 at baseline & Median (Quantiles) & $2(0 \sim 4)$ & $2(0 \sim 4)$ & 0.672 \\
\cline { 2 - 4 } & $0 \sim 4$ & $66(80.5)$ & $287(75.9)$ & \\
& $5 \sim 9$ & $13(15.9)$ & $73(19.3)$ & \\
\hline & $10 \sim 27$ & $3(3.7)$ & $18(4.8)$ & \\
\hline \multirow{2}{*}{ GAD-7 at baseline } & Median (Quantiles) & $1(0-2)$ & $1(0-3)$ & 0.336 \\
\cline { 2 - 4 } & $0 \sim 4$ & $70(85.4)$ & $328(86.8)$ & \\
\hline & $5 \sim 9$ & $9(11.0)$ & $45(11.9)$ & \\
\hline & $10 \sim 21$ & $3(3.7)$ & $5(1.3)$ & \\
\hline
\end{tabular}

PHQ-9, Patient Health Questionnaire-9 depression scale; GAD-7, Generalized Anxiety Disorder-7 scale.

In the HPV-positive group, all 82 participants completed the second self-administered questionnaire. The Wilcoxon's test showed positive HPV results had no significant impact on the scores of PHQ-9 $(Z=-1.399$, $p=0.162)$ and GAD-7 $(Z=-0.383, p=0.702)$. HPV subtypes $16 / 18$ positivity did not change the results (Figure 2).

After further evaluation by colposcopy, with or without biopsy, 69 participants (84\%) completed the third questionnaire. The Friedman's test showed statistical differences of the PHQ-9 scores at three time-points with a descending trend, while the Wilcoxon's test showed no difference in PHQ-9 scores $(Z=-0.184, p=$ $0.854)$ and GAD-7 scores $(Z=-0.022, p=0.983)$ before and after the colposcopy was performed (Figure 3A, 3B). To investigate the impact of different diagnoses, we divided 69 participants into three subgroups: 11 in the HSIL group (i.e., the biopsy confirmed HSIL or above, and the colposcopy diagnosed HSIL or above without biopsy), 17 in the LSIL group (i.e., the biopsy confirmed LSIL and colposcopy diagnosed LSIL without biopsy), 41 in the cervicitis group (i.e., the biopsy confirmed cervicitis and the colposcopy diagnosed cervicitis without biopsy). The PHQ-9 score in the cervicitis group was significantly lower after the colposcopy compared to the baseline $(Z=-2.512, p=0.012)$, while the PHQ-9 and GAD-7 scores in the 
LSIL or HSIL groups remained unchanged. The change of scores of the three subgroups is shown in Figure 3C, 3D, 3E, 3F. Other factors that may influence the PHQ-9 score were evaluated by binomial Logistic regression. After adjusting for compounds like baseline score and multi-infection, education level of postgraduate was found to be the independent risk factor for elevated PHQ-9 score (Table 4). No factor was associated with the change of GAD-7 scores (data not shown).

Table 4. factors associated with elevated PHQ-9 score

\begin{tabular}{lllll}
\hline & OR & $95 \%$ CI & aOR & $95 \%$ CI \\
\hline Baseline PHQ-9 & 0.768 & $0.562-1.050$ & 0.649 & $0.432-0.975$ \\
HPV 16/18 + & 0.648 & $0.159-2.637$ & 0.252 & $0.034-1.838$ \\
\hline Multi-infected & 1.143 & $0.210-6.219$ & 5.721 & $0.467-70.084$ \\
\hline Final result & & & & \\
\hline Cervicitis & 1 & - & 1 & - \\
\hline LSIL & 1.400 & $0.385-5.090$ & 0.807 & $0.115-5.641$ \\
\hline HSIL & 0.800 & $0.133-4.803$ & 9.537 & $0.905-100.539$ \\
\hline Education & & & & \\
\hline Less than high school & 1 & - & 1 & - \\
\hline College graduate & 1.882 & $0.358-9.895$ & 5.082 & $0.585-25.921$ \\
\hline Postgraduate & 6.400 & $0.891-45.992$ & 86.702 & $4.541-1655.497 *$ \\
\hline Knowing CC & 0.370 & $0.109-1.253$ & 0.284 & $0.054-1.487$ \\
\hline Knowing HPV & 0.442 & $0.110-1.769$ & 0.157 & $0.015-1.654$ \\
\hline
\end{tabular}

LSIL, low-grade squamous intraepithelial lesion; HSIL, high-grade squamous intraepithelial lesion; CC, cervical cancer; aOR, adjusted OR.

$* \mathrm{p}<0.05$

\section{Discussion}

Testing positive for HPV followed by instant colposcopy appears to be irrelevant to women's psychological distress during a routine prenatal visit. Our findings are consistent with some previous studies regarding non-pregnant populations showing that HPV positivity with normal cytology is not associated with elevated anxiety or depression scores, $(13,24)$ while inconsistent with other observational studies. $(10,25,26)$ One study found that women who tested positive for HPV 16/18 with normal cytology had significantly higher anxiety score than those of non-16/18 HPV positive women, and the score continued to rise two months after the notification. (25) Despite their small sample size of the HPV-16/18-positive-and-cytology-normal group similar to our study $(n=19$ vs $n=23)$. We did not find a change of score of GAD-7 and PHQ-9 within each group and between the two groups. Considering the lack of awareness of HPV and cervical cancer among the pregnant women in our study, and the association between the postgraduate degree and elevated depression score, it is possible that not 
understanding the screening results is the primary reason for lower anxiety level. With no populationbased screening and vaccination programmes, Chinese women had little access to proper education on the topic. A qualitative study confirmed our hypothesis by showing that women with low-to-normal anxiety were more likely to be unaware of being tested for HPV and to perceive their results to be "not serious", compared to women with high anxiety. (27) Other cross-sectional studies were likely to be biased because no baseline status of psychological distress was evaluated. $(10,26)$ As showed by Kitchener's study, revealing the positive HPV result did not increase psychological distress among women whose HPV test result was positive, suggesting that factors other than awareness of the positive HPV result may have contributed to the higher psychological distress level of the HPV-positive women compared to HPV-negative women. (13) The distribution of anxiety level and depression level between the HPV-positive and HPV-negative groups at baseline were nonsignificant in our study, possibly because the participants were pregnant women in their second trimester, which differs from non-pregnant populations. In a developing country with such a large population like China, pregnant women got an average 7-11 times of prenatal visits with only 10 minutes at most of one-on-one time with their doctor each time they visit.(28) Such a short duration of counselling often left questions unanswered. Women were otherwise unaware of their own situation had the doctor not brought that up. That very attitude differs from those non-pregnant women who spontaneously seeking a cervical cancer screening at the outpatient clinic.

Additionally, women with positive HPV results had stable distress level even after a diagnosis of cervical lesion, LSIL or HSIL, was detected by colposcopy. Low knowledge of cervical pre-cancer and HPV might partially account for this. Some studies have shown that colposcopy related anxiety levels declined significantly over time, (29) while other studies found that to remain the same. (30)

Other than lack of awareness of HPV, one reason of the unchanged GAD-7 and PHQ-9 scores among HPV-positive women may have been that women were given the information of the high prevalence of HPV at the result notification on request, which may help eliminate some fear and anxiety. (31)

As shown in our study, women who initiated sexual intercourse early (before the age of 21), had multiple lifetime sexual partners, and prefer to take emergency contraceptive pills (might be an indicator of unfavorable to use a condom), were more likely to be infected with HPV. With the increasing taking-on of the westernized lifestyle, the infection rate for women of child-bearing age would be even higher in the near future, especially in the non-pregnant population who have less access to cervical cancer screening. Sixty percent of pregnant women reported having heard of cervical cancer in our study. The number went down to 7.6 percent when regarding the causal relationship between that and HPV. According to the national cervical cancer screening guidelines published in 2017, women aged 25 to 64 years were recommended to undergo cytology screening every 3 years, (5) that leaves half of the study participants to meet the criteria of un-screened or under-screened. Because there is no organized mass screening programme in mainland China, the minority of women are reached by local health facilities as part of some organized campaigns within different provinces and cities, while others have no choice but to request the screening on their own, or to be opportunistic screened by health practitioners when coming 
to outpatient clinic for other reasons. (32) While it is well-understood that the opportunistic screening could fail to reach women most at risk, one way to overcome the lack of national organized cervical cancer screening would be to take advantage of prenatal checkups to screen those women who receive suboptimal or no screening except during pregnancy.

\section{Study limitations}

To our knowledge, this is the first observational study on psychological distress of testing positive for HPV in cervical cancer screening among pregnant women, but with a relatively small sample size. There are a few limitations to our study. First, fourteen participants (17\%) in the HPV-positive group were lost to follow-up. As a previous study showed that women who chose not to follow up had higher anxiety, our results may therefore be biased (33). Another limitation would be that all women were recruited in Shanghai, one of the top developed cities in China, which may not represent other areas with lower economic levels.

\section{Clinical Implications}

Previous studies on the psychological impacts of cervical cancer screening, observational or interventional, were solely based on the non-pregnant population, and were mostly focused on women in the developed countries. Our findings shed light on pregnant women's stable psychological state in the progress of HPV testing and colposcopy, which can be easily carried out in the prenatal-care visit to compensate for the lack of organized screening programmes in the developing countries.

\section{Conclusions}

Despite its preliminary character, this study shows that HPV testing is not as distressing as people thought. Routine prenatal care is a promising opportunity to increase screening uptake among unscreened and under-screened women, without causing unintended anxiety and depression to HPVpositive women.

\section{List Of Abbreviations}

IARC, International Agency for Research on Cancer; ASCCP, American Society for Colposcopy and Cervical Pathology; STI, sexually transmitted infection; NILM, Negative for intraepithelial lesion or malignancy; ASC-US, atypical squamous cells of undetermined significance; LSIL, low-grade squamous intraepithelial lesion; HISL, high-grade squamous intraepithelial lesion; GAD-7, Generalized Anxiety Disorder-7 scale, PHQ-9, Patient Health Questionnaire-9; CNY, Chinese Yuan; OC, oral contraceptives; IUD, intrauterine device; CC, cervical cancer.

\section{Declarations}




\section{Ethics approval and consent to participate}

The study was approved by Ren Ji Hospital Ethics Committee (2018[026]). All methods were carried out in accordance with the rules of the Declaration of Helsinki. All participants provided written informed consent.

\section{Consent for publication}

Not applicable.

\section{Availability of data and materials}

The data that support the findings of this study are not openly available due to human data and are available from the corresponding author upon reasonable request.

\section{Competing interests}

The authors declare that they have no competing interests.

\section{Funding}

This study was funded by grants from National Key R\&D Program of China (2016YFC1302900), National Natural Science Foundation of China (81974454 and 81772770), Program of Shanghai Hospital Development Center (16CR2001A), Science and Technology Commission of Shanghai Municipality (18441904800), Shanghai Municipal Commission of Health and Family Planning (2017ZZ02016), Shanghai Municipal Key Clinical Specialty, and Shanghai Municipal Commission of Health and Family Planning and Program of Shanghai Hospital Development Office (ZY(2018-2020)-FWTX-3006).

\section{Author contributions}

Conceptualization, D.W. and Q.L.H.; Methodology, L.J.H., Z.Y., and Y.H.; Investigation, H.Y.F., G.L.Y., and H.Z.B.; Funding Acquisition, D.W. and Q.L.H.; Resources, D.W. and Q.L.H.; Supervision, L.J.H., Q.L.H., and D.W.; Draft, H.Y.F. and Q.L.H.; All authors contributed to the final version of the manuscript.

\section{Acknowledgements}

We appreciate all the pregnant women who kindly gave up their time to take part in our study.

\section{References}


1. International Agency for Research on Cancer WHO. Cancer Today. Data source: GLOBOCAN 2020 2020 [Available from: https://gco.iarc.fr/today/.

2. United Health Foundation. Trend: Cervical Cancer Screening, United States 2020 [Available from: https://www.americashealthrankings.org/explore/health-of-women-andchildren/measure/cervical_cancer_screen_women/state/ALL.

3. NHS Cervical Screening Programme. Cervical screening: quarterly coverage data reports 2020 2020 [Available from: https://www.gov.uk/government/publications/cervical-screening-quarterlycoverage-data-reports-2020.

4. Feng RM, Zong YN, Cao SM, Xu RH. Current cancer situation in China: good or bad news from the 2018 Global Cancer Statistics? Cancer Commun. 2019;39:12.

5. Chinese Preventive Medicine Association. [Comprehensive prevention and control guidelines for cervical cancer in China]. Beijing: People's Medical Publishing House; 2017.

6. Ogilvie GS, van Niekerk D, Krajden M, Smith LW, Cook D, Gondara L, et al. Effect of screening with primary cervical HPV testing vs cytology testing on high-grade cervical intraepithelial neoplasia at 48 months: the HPV FOCAL randomized clinical trial. JAMA. 2018;320(1):43-52.

7. Kitchener HC, Almonte M, Thomson C, Wheeler P, Sargent A, Stoykova B, et al. HPV testing in combination with liquid-based cytology in primary cervical screening (ARTISTIC): a randomised controlled trial. The Lancet Oncology. 2009;10(7):672-82.

8. Zhang J, Zhao Y, Dai Y, Dang L, Ma L, Yang C, et al. Effectiveness of High-risk Human Papillomavirus Testing for Cervical Cancer Screening in China: A Multicenter, Open-label, Randomized Clinical Trial. JAMA Oncology. 2021;7(2):263-70.

9. Perkins RB, Guido RS, Castle PE, Chelmow D, Einstein MH, Garcia F, et al. 2019 ASCCP Risk-Based Management Consensus Guidelines for Abnormal Cervical Cancer Screening Tests and Cancer Precursors. Journal of Lower Genital Tract Disease. 2020;24(2):102-31.

10. McCaffery K, Waller J, Forrest S, Cadman L, Szarewski A, Wardle J. Testing positive for human papillomavirus in routine cervical screening: Examination of psychosocial impact. BJOG: An International Journal of Obstetrics and Gynaecology. 2004;111(12):1437-43.

11. McCaffery K, Waller J, Nazroo J, Wardle J. Social and psychological impact of HPV testing in cervical screening: A qualitative study. Sexually Transmitted Infections. 2006;82(2):169-74.

12. McBride E, Tatar O, Rosberger Z, Rockliffe L, Marlow LM, Moss-Morris R, et al. Emotional response to testing positive for human papillomavirus at cervical cancer screening: a mixed method systematic review with meta-analysis. Health Psychology Review. 2020:1-35. 
13. Kitchener HC, Fletcher I, Roberts C, Wheeler P, Almonte M, Maguire P. The psychosocial impact of human papillomavirus testing in primary cervical screening-a study within a randomized trial. Int $J$ Gynecol Cancer. 2008;18(4):743-8.

14. McNeil TF, Kaij L, Maimquist-Larsson A. Women with nonorganic psychosis: pregnancy's effect on mental health during pregnancy. Acta Psychiatrica Scandinavica. 1984;70(2):140-8.

15. Gu C, Chen W-T, Zhang Q, Chow KM, Wu J, Tao L, et al. Exploring Chinese Women's Perception of Cervical Cancer Risk as It Impacts Screening Behavior: A Qualitative Study. Cancer Nursing. 2017;40(4):E17-E25.

16. Zhong QY, Gelaye B, Zaslavsky AM, Fann JR, Rondon MB, Sanchez SE, et al. Diagnostic Validity of the Generalized Anxiety Disorder-7 (GAD-7) among Pregnant Women. Plos One. 2015;10(4):17.

17. Simpson W, Glazer M, Michalski N, Steiner M, Frey BN. Comparative Efficacy of the Generalized Anxiety Disorder 7-Item Scale and the Edinburgh Postnatal Depression Scale as Screening Tools for Generalized Anxiety Disorder in Pregnancy and the Postpartum Period. Can J Psychiat-Rev Can Psychiat. 2014;59(8):434-40.

18. Sidebottom AC, Harrison PA, Godecker A, Kim H. Validation of the Patient Health Questionnaire (PHQ)-9 for prenatal depression screening. Archives of Women's Mental Health. 2012;15(5):367-74.

19. NICE. Antenatal and postnatal mental health: clinical management and service guidance 2014 [Available from: https://www.nice.org.uk/guidance/cg192/chapter/1-Recommendations.

20. American College of Obstetricians and Gynecologists. Screening for perinatal depression. ACOG Committee Opinion No 757. Obstet Gynecol. 2018;132(5):e208-e12.

21. Kroenke K, Spitzer RL, Williams JBW, Lowe B. The Patient Health Questionnaire Somatic, Anxiety, and Depressive Symptom Scales: a systematic review. General Hospital Psychiatry. 2010;32(4):345-59.

22. Kroenke K, Spitzer RL, Williams JB. The PHQ-9: validity of a brief depression severity measure. Journal of general internal medicine. 2001;16(9):606-13.

23. Zhao FH, Tiggelaar SM, Hu SY, Xu LN, Hong Y, Niyazi M, et al. A multi-center survey of age of sexual debut and sexual behavior in Chinese women: Suggestions for optimal age of human papillomavirus vaccination in China. Cancer Epidemiol. 2012;36(4):384-90.

24. Andreassen T, Hansen BT, Engesaeter B, Hashim D, Stoer NC, Trope A, et al. Psychological effect of cervical cancer screening when changing primary screening method from cytology to high-risk human papilloma virus testing. Int J Cancer. 2019;145(1):29-39.

25. Alay I, Kaya C, Karaca I, Yildiz S, Baghaki S, Cengiz H, et al. The effect of being diagnosed with human papillomavirus infection on women's sexual lives. Journal of Medical Virology. 2020;92(8):1290-7. 
26. McBride E, Marlow LAV, Forster AS, Ridout D, Kitchener H, Patnick J, et al. Anxiety and distress following receipt of results from routine HPV primary testing in cervical screening: The psychological impact of primary screening (PIPS) study. International Journal of Cancer. 2020;146(8):2113-21.

27. McBride E, Marlow LAV, Bennett KF, Stearns S, Waller J. Exploring reasons for variations in anxiety after testing positive for human papillomavirus with normal cytology: a comparative qualitative study. Psycho-Oncology. 2021;30(1):84-92.

28. Qi H, Yang H. Guidelines for pre-pregnancy and pregnancy care (2018). Chinese Journal of Obstetrics \& Gynecology. 2018;53(01):7-13.

29. O'Connor M, Gallagher P, Waller J, Martin CM, O'Leary JJ, Sharp L. Adverse psychological outcomes following colposcopy and related procedures: a systematic review. BJOG : an international journal of obstetrics and gynaecology. 2016;123(1):24-38.

30. O'Connor M, O'Leary E, Waller J, Gallagher P, D'arcy T, Flannelly G, et al. Trends in, and predictors of, anxiety and specific worries following colposcopy: a 12-month longitudinal study. Psycho-Oncology. 2016;25(5):597-604.

31. Hendry M, Pasterfield D, Lewis R, Clements A, Damery S, Neal RD, et al. Are women ready for the new cervical screening protocol in England A systematic review and qualitative synthesis of views about human papillomavirus testing. British Journal of Cancer. 2012;107(2):243-54.

32. Gu C, Chan CWH, Twinn S. How sexual history and knowledge of cervical cancer and screening influence Chinese women's screening behavior in mainland China. Cancer nursing. 2010;33(6):445-53.

33. French DP, Maissi E, Marteau TM. Psychological costs of inadequate cervical smear test results. $\mathrm{Br}$ J Cancer. 2004;91(11):1887-92.

\section{Figures}




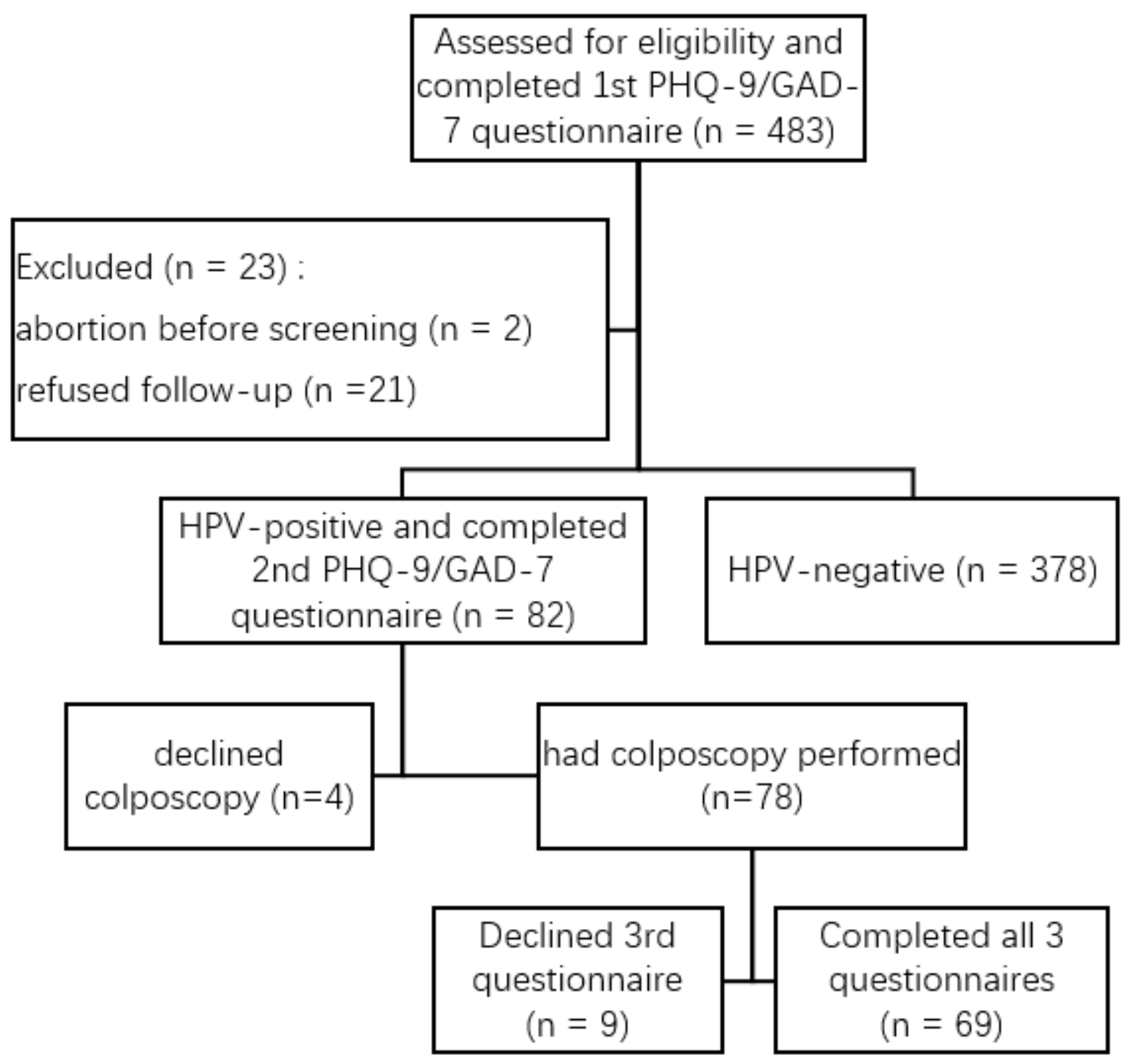

Figure 1

Study flow chart. 
A

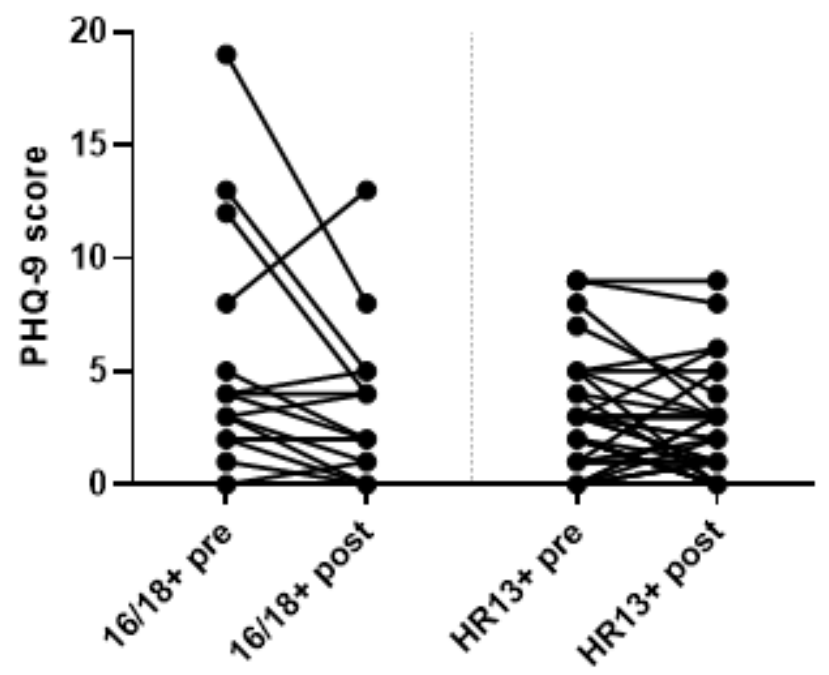

B

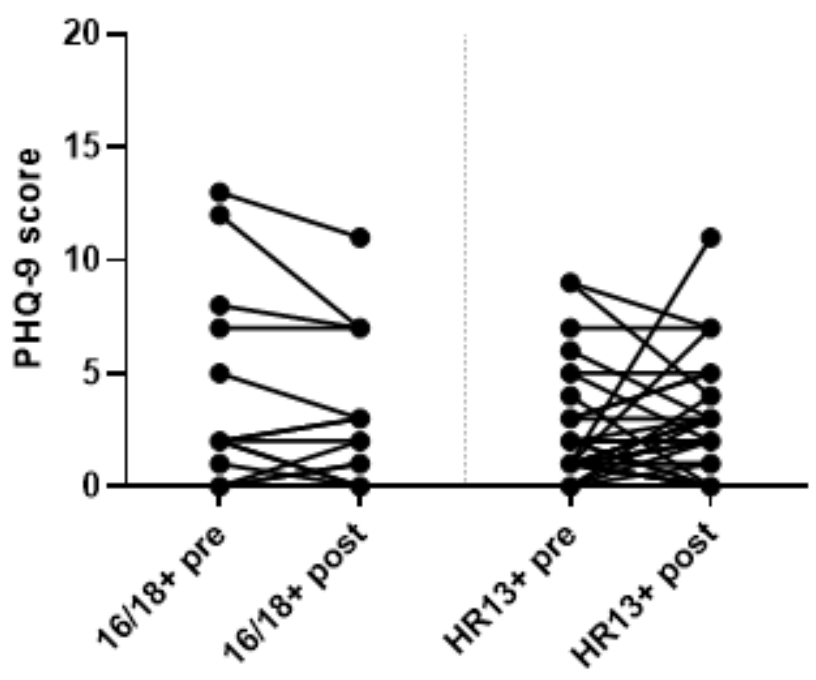

Figure 2

PHQ-9 and GAD-7 scores before and after receiving positive HPV results divided by HPV subtypes. (A) PHQ-9 scores. (B) GAD-7 scores. HR13, other 13 HPV subtypes, including subtypes $31,33,35,39,45,51$, $52,53,56,58,59,66$, and 68 . 

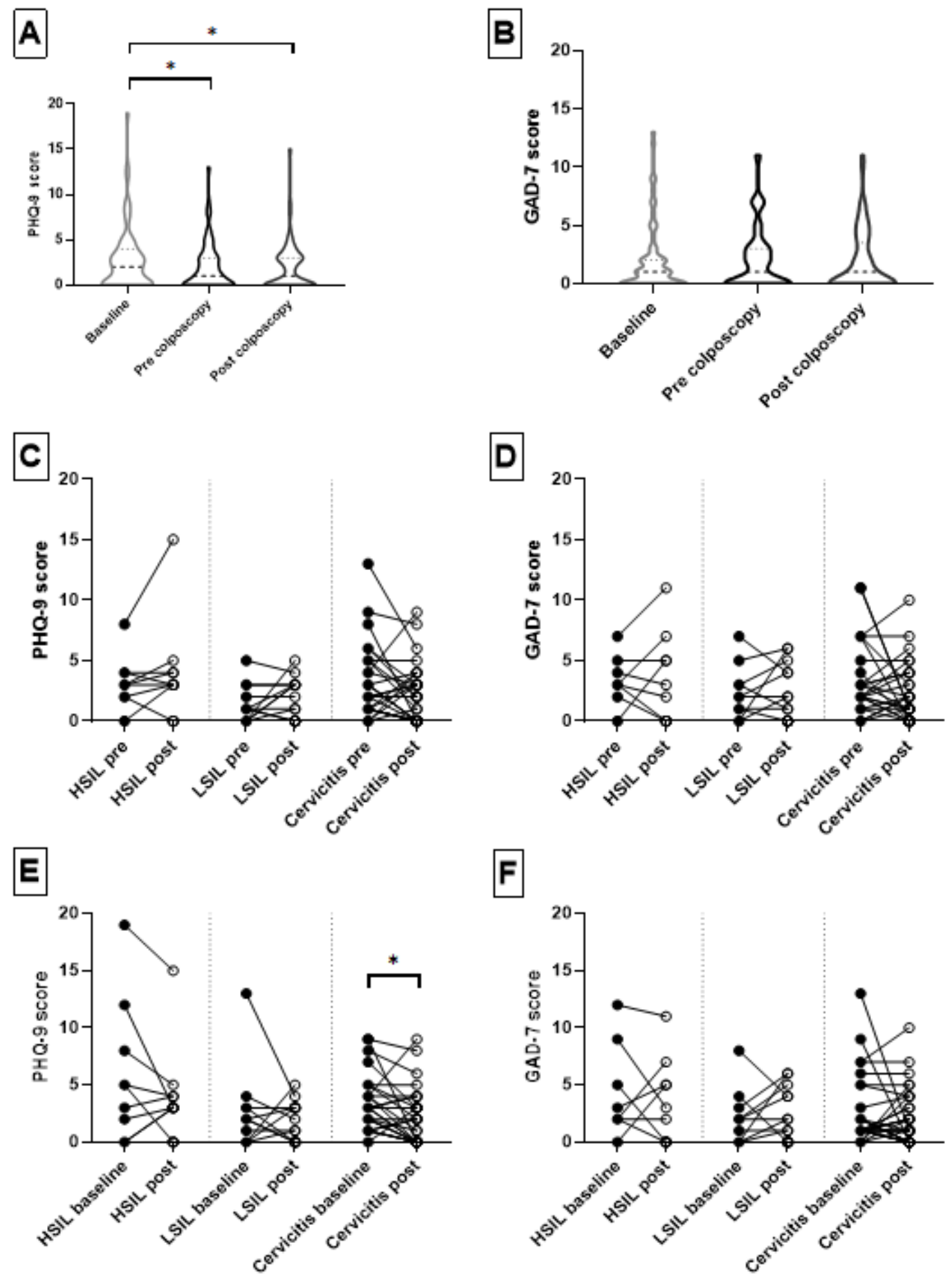

\section{Figure 3}

PHQ-9 and GAD-7 scores at different time-points. (A) (B) PHQ-9 scores and GAD-7 scores of HPV-positive women at three time-points. (C) (D) PHQ-9 scores and GAD-7 scores of HPV-positive women before and after colposcopy, classified by diagnoses. (E) (F) PHQ-9 scores and GAD-7 scores of HPV-positive women at baseline and after colposcopy, classified by diagnoses. LSIL, low-grade squamous intraepithelial lesion; HSIL, high-grade squamous intraepithelial lesion 